\title{
FACTORS ASSOCIATED WITH CHEMICAL PESTICIDE USE AMONG FARMERS IN EASTERN PART OF CAMBODIA
}

\author{
Vong Pisey, Wongsa Laohasiriwong, \\ Teerasak Phajan, Somsak Pitaksanurat \\ Faculty of Public Health, Khon Kaen University, Thailand
}

\begin{abstract}
BACKGROUND: Chemical pesticides are known to have adverse impact on human health. However, little is known about the magnitude and factors influencing chemical pesticide use in Cambodia. The study aimed to describe and determine factors influencing chemical pesticide use among farmers in the Eastern part of Cambodia.

SUBJECT AND METHODS: This was a cross-sectional study. A total of 287 farmers were selected by multistage random sampling proportional to size of the population from 8 communes in the Eastern part of Cambodia. The questionnaire was developed to measure variables under study. A multiple logistic regression was applied to estimate the factors influencing chemical pesticide use.

RESULTS: $53.66 \%$ of the sample was female. Mean age $=41.01$, and $\mathrm{SD}=$ 10.8 years old. The average monthly income was 460,000 Riel (112 US\$). The illiteracy rate was $15.68 \%$. All of these farmers planted rice, cassava and caisim. $72.13 \%$ of all farmers used chemical pesticide. $68.13 \%$ of 182 rice farmers used 2,4-D. 92.48\% of 133 cassava farmers used glyphosate, and $54.89 \%$ used $2,4-\mathrm{D}$. $71.43 \%$ of 35 caisim farmers used fipronil, and $68.57 \%$ used malathion. Factors significantly associated with chemical pesticide use were illiteracy $(\mathrm{OR}=2.60 ; 95 \% \mathrm{CI}=1.02$ to $6.62 ; \mathrm{p}=0.045)$ and increase in farm size per $\mathrm{m}^{2}(\mathrm{OR}=2.12 ; 95 \% \mathrm{CI}=1.59$ to 2.84 ; $\mathrm{p}<0.001$ ).

CONCLUSION: Chemical pesticide use was very high in Cambodia. Some used prohibited chemical. Illiteracy and farm size affect chemical pesticide use among farmers in Cambodia.
\end{abstract}

Keywords: chemical pesticide use, Cambodia, farmer 